\title{
Control of Refractory Recurrent Ventricular Tachyarrhythmias by Artificial Cardiac Pacing \\ A Preliminary Report on the use of His Bundle Electrogram in Determining the Indication
}

Chuichi KaWAi, M.D.

$\mathbf{O}$ $\mathrm{NE}$ OF the most challenging problems in the clinical medicine at this time is to suppress or prevent by an electrical pacemaker repetitive, often fatal, ventricular tachyarrhythmias that cannot be suppressend with the conventional antiarrhythmic drugs. It is well established that ventricular tachyarrhythmias arising in the course of complete atrioventricular (A-V) block can be eliminated by pacing the ventricles at rates faster than the idioventricular rhythm. Moreover, it has been reported by several investigators that refractory ventricular tachyarrhythmias even in the absence of A-V block:can be successfully managed with temporary ${ }^{2-8}$ as well as permanent ${ }^{7,9-13}$ atrial or ventricular pacemaking. The potential danger, however, exists whenever artificial pacing is used unless cardiac excitation or patients' own beat is eliminated completely! ${ }^{4}$ Therefore, as Greenfield at al. stated, ${ }^{15}$ the risk of producing ventricular fibrillation is greatest in the very patients who are the most likely to be treated with an electrical pacemaker to suppress ventricular tachyarrhy thmias.

This paper describes the author's experience of successful treatment of refractory recurrent ventricular tachyarrhythmias in a group of

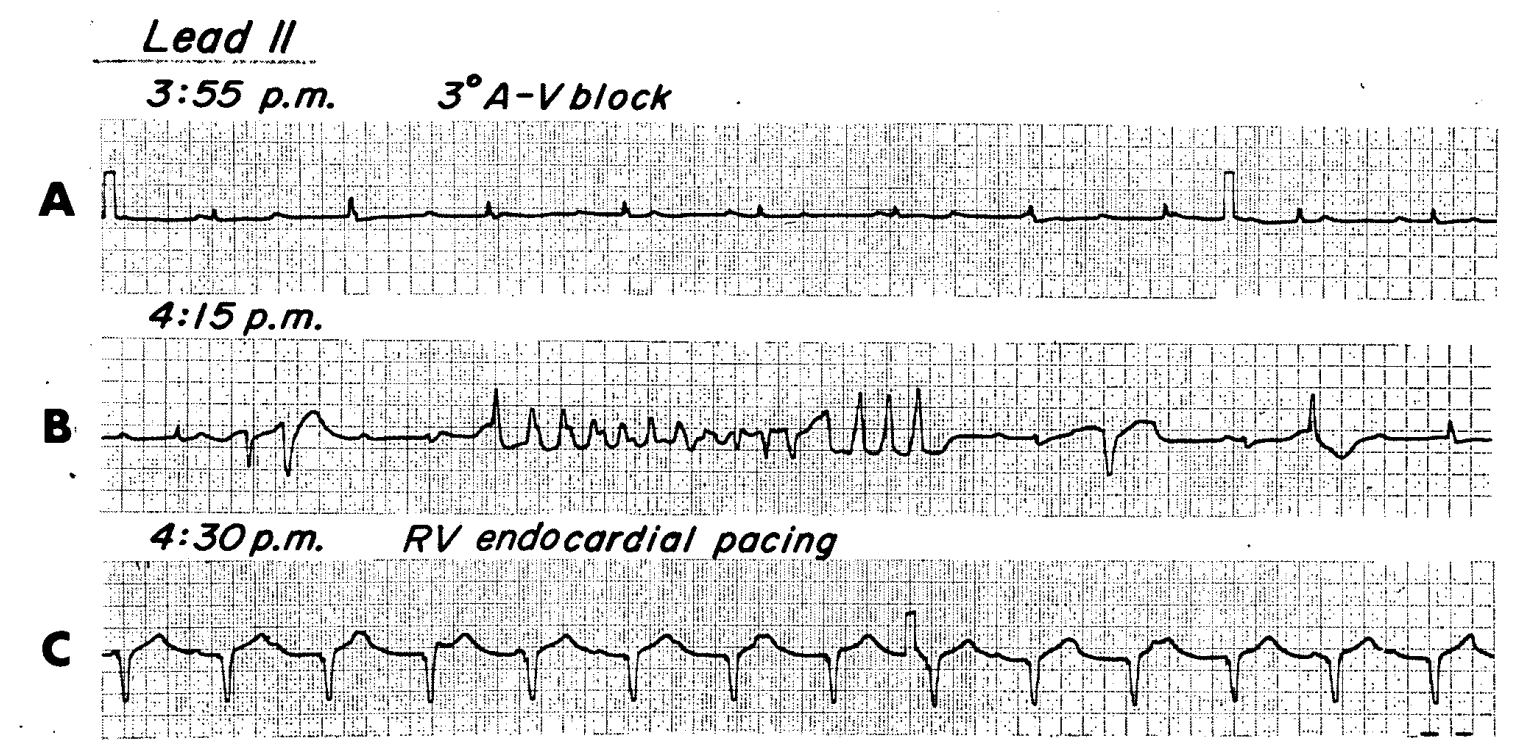

Fig.1. Electrocardiograms (Lead II). Case 1, F. O. A. Complete A-V block. B. Runs of ventricular tachyarrhythmias in the presence of complete A-V block. C. Endocardial pacing in the right ventricle $(\mathrm{RV})$.

Key Words:

Artificial cardiac pacing

Recurrent ventricular tachyarrhythmia

His bundle electrogram patients with or withou A-V block by means of temporary, usually followed by permanent pacemaking. The use of the His bundle electrogram in determining indications for this treatment is also

The 3rd Division, Department of Internal Medicine, Osaka Medical College, Takatsuki, Osaka, Japan. 

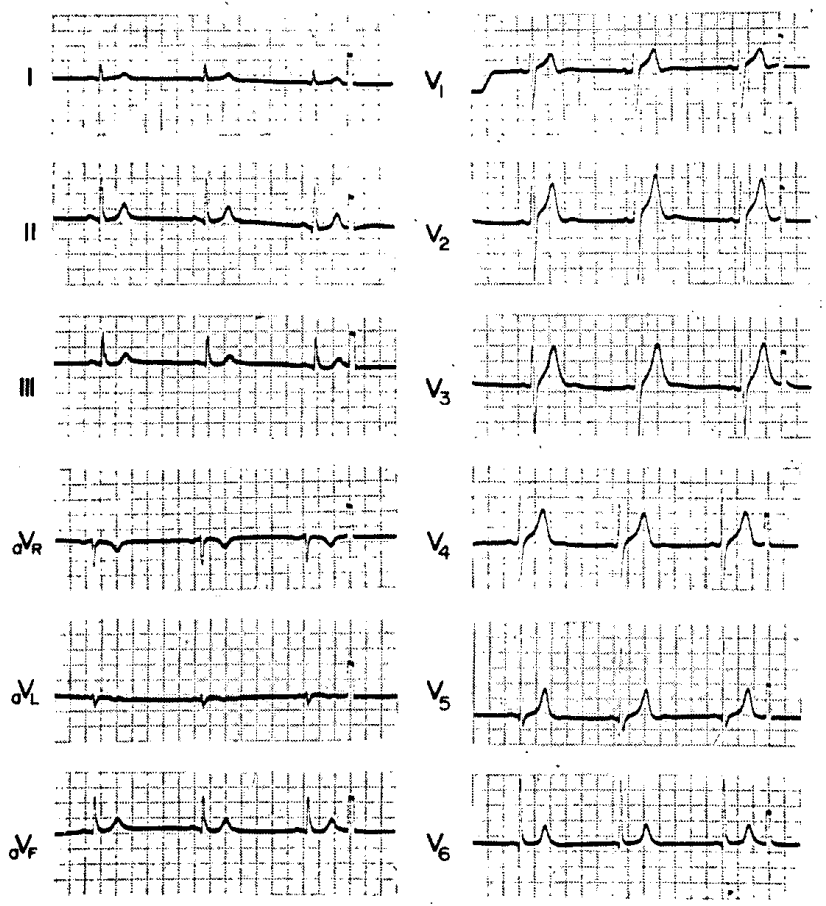

Fig.2. Twelve leads electrocardiogram. Case 2, T. Y. Sinus brady cardia.

discussed

\section{CASE RePORT}

1) Patient with complete A-V block
Case 1. F. O.

A 72-year-old woman had an episode of precordial pain associated with nausea and choking sensation 4 years prior to admission. She has had occasional fainting spell with increased intensity of convulsion for the past 3 years. In normal sinus rhythm the electrocardiogram showed left bundle branch block. Diagnosis of bilateral bundle branch block was made on the basis of prolonged $\mathrm{H}-\mathrm{Q}(\mathrm{V})$ interval $(62 \mathrm{msec}$.) in the His bundle electrogram. During complete A-V block the patient developed Stokes-Adams attacks due to recurrent episodes of ventricular tachyarrhythmias or prolonged asystole, or both. The episodes of ventricular tachyarrhythmias were successfully controled by temporary pacemaking (Fig. 1) and completely prevented by implantation of a permanent pacemaker.

2) Patient without complete A-V block

Case 2. T. Y.

A 47-year-old man with sinus bradycardia (Fig. 2) suddenly developed Stokes-Adams attack due to bouts of ventricular fibrillation preceded by ectopic atrial rhythm with premature ventricular contractions. The ventricular tachyarrhythmias were spontaneously reverted to normal sinus rhythm following a short runs of atrial fibril-

A

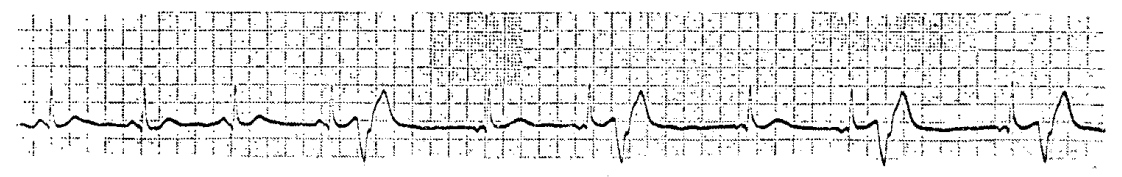

B

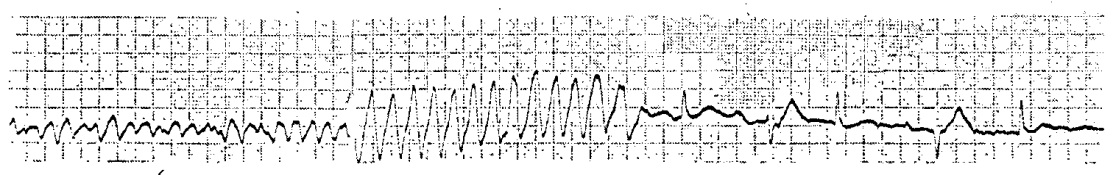

C
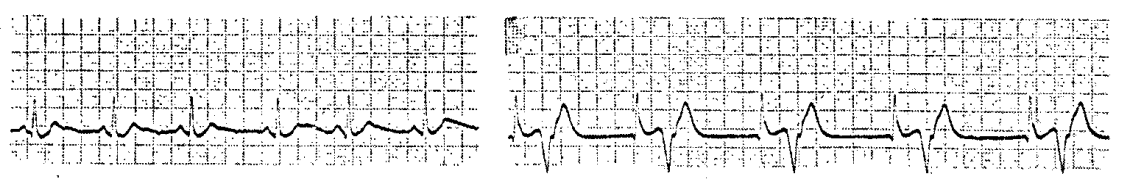

Lidocaine i. v. infusion

D

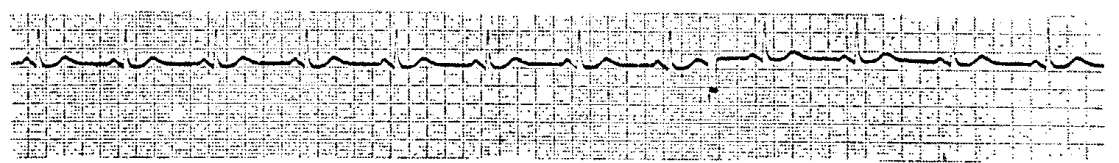

Fig.3. Serial electrocardiograms during episodes of ventricular tachyarrhythmia (Jan. 26, 1971). Case 2, T. Y. Lead II. A. Sinus rhythm followed by ectopic atrial rhythm with premature ventricular contractions in bigeminy. B. Runs of ventricular tachyarrhythmia spontaneously reverted to atrial fibrillation with aberrant ventricular conduction. C. Sinus rhythm and recurrence of A-V junctional rhythm with premature ventricular contractions in bigeminy. Ventricular tachyarrhythmia recurred (not shown). D. Elimination. of ventricular irritability by intravenous lidocaine. 
2:00 p.m.

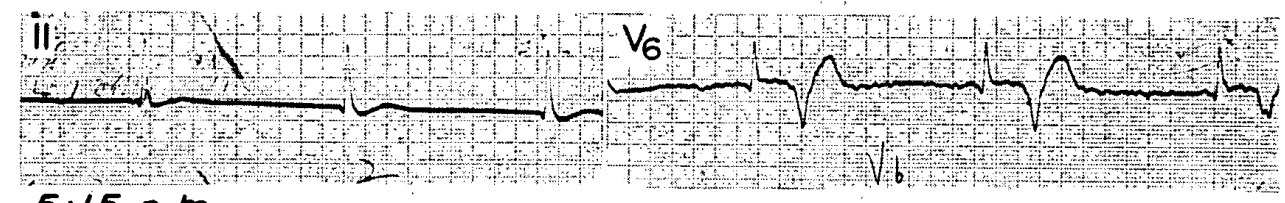

$5: 15$ p.m.

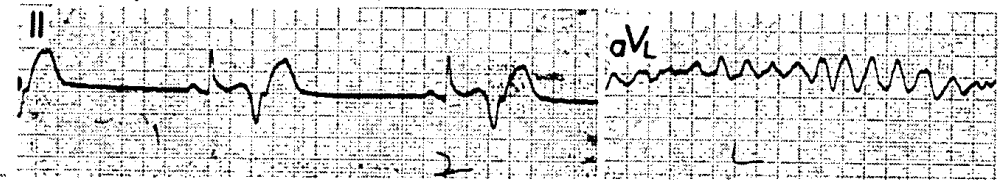

Fig.4. Case 2, T. Y. During episode of ventricular fibrillation 10 months prior to Fig.3. Note very similar serial changes (Mar. 19, 1970).

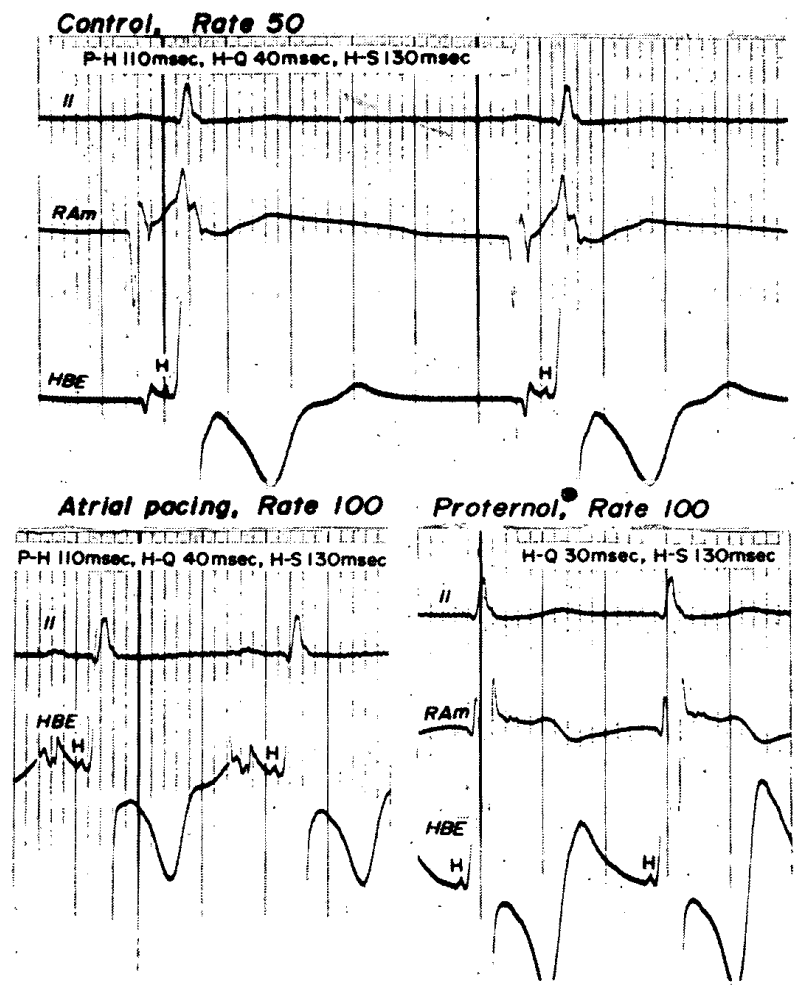

Fig.5. His bundle electrogram (HBE). Case 2, T. Y. (upper) Control recording. (lower left) Atrial pacing at a rate of 100 per minute. No change in $\mathrm{P}-\mathrm{H}, \mathrm{H}-\mathrm{Q}$ and $\mathrm{H}-\mathrm{S}$ intervals. No dropped beat. (lower right) A-V junctional tachycardia at a rate of 100 per minute by intravenous -isoproterenol (Proternol ${ }^{\circledR}$ ). Note $\mathrm{H}$ waves preceding QRS complexes in the absence of $\mathrm{P}$ waves. II: Lead II electrocardiogram. RAm: Unipolar intra-right atrial (middle) electrogram.

lation with aberrant ventricular conductions. A-V junctional rhy thm with premature ventricular contractions in bigeminy replaced normal sinus rhythm, and ventricular fibrillation ensued again. The ventricular irritability was successfully controled by intravenous infusion of lidocaine (Fig. 3). The patient experienced the similar attack a year ago (Fig. 4), but was in good condition between the attacks. There was no cardiac enlargement. The His bundle electrogram (Fig. 5) revealed normal $\mathrm{P}(\mathrm{A})-\mathrm{H}, \mathrm{H}-\mathrm{Q}(\mathrm{V})$ and $\mathrm{H}-\mathrm{S}$ intervals, $110 \mathrm{msec}$, $40 \mathrm{msec}$ and $130 \mathrm{msec}$, respectively (upper). Right atrial pacing at a rate of $100 / \mathrm{min}$. caused no lengthening or block in the $\mathrm{P}(\mathrm{A})-\mathrm{H}$ and $\mathrm{H}-\mathrm{Q}(\mathrm{V})$ intervals (lower, left), but at a rate faster than 100 per minute atrial contractions occasionally dropped. Increase in the heart rate more than $75 / \mathrm{min}$. by isoproterenol resulted in the $\mathrm{A}-\mathrm{V}$ junctional tachycardia preceded by the $H$ wave with complete absence of the $\mathrm{P}(\mathrm{A})$ waves which were confirmed by intra-atrial electrocardiogram (RAm) (lower, right). A permanent demand pacemaker has successfully prevented StoksAdams attacks for the past 17 months (Fig. 6).

Case 3. Y.S.

A 40-year-old man, details of whom were reported elsewhere, ${ }^{16}$ developed ventricular tachycardia and fibrillation triggered by a premature ventricular contraction on the $T$ wave of the preceding normal sinus beat ( $\mathrm{R}$ on $\mathrm{T}$ phenomenon). The ventricular fibrillation was terminated spontaneously with two successive premature ventricular contracions succeeded by supraventricular escaped beats (Fig. 7). The bout of ventricular tachyarrhythmia developed all of a sudden during normal sinus rhythm 30 minustes after taking a meal, when the patient complained of epigastric discomfort. In some occasions, usually after a meal, bradyarrhythmia due to sinoatrial block and premature ventricular contractions (Fig. 8) preceded the Stokes-Adams attacks. The electrocardiogram during regular sinus rhythm (Fig. 9) revealed first degree A-V block (P-Q $0.28 \mathrm{sec}$.) and a queer $\mathrm{S}$-T elevation in leads II aVF and $V_{1,2}$. Slight cardiomegaly (CTR: 0.51) was noted on the chest X-ray film. There were no signs and symptoms suggestive of myocardial infarction, angina pectoris or pericarditis. The His bundle electrogram (Fig. 10) demonstrated 


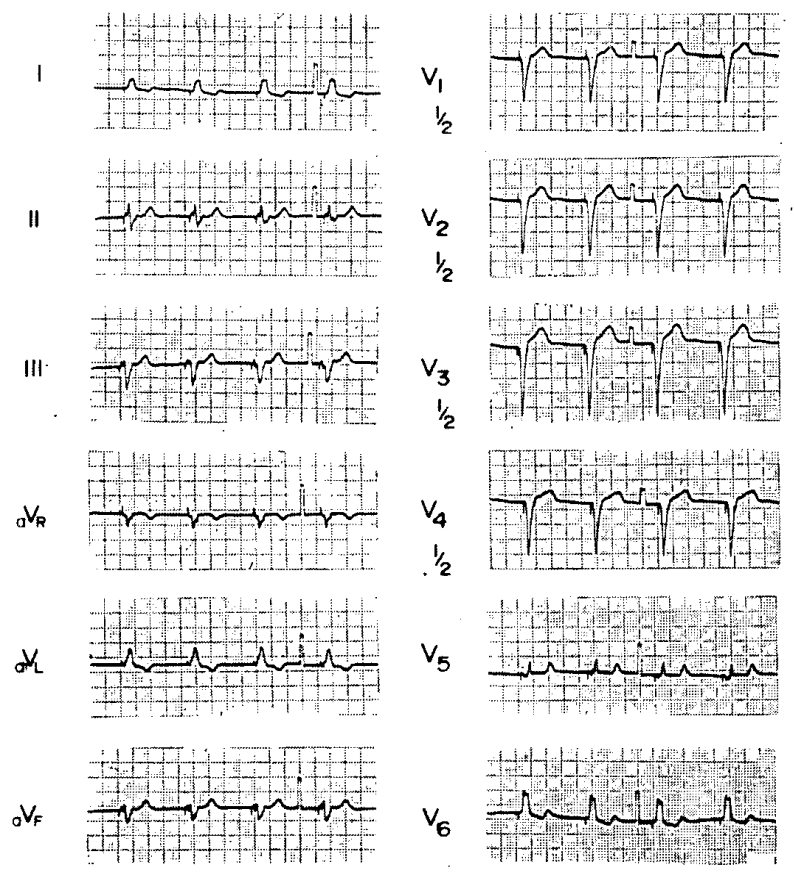

Fig.6. Twelve leads electrocardiogram. Case 2, T. Y. After implantation of permanent pacemaker.

lengthening of the $\mathrm{P}(\mathrm{A})-\mathrm{H}$ (190 msec.) and the $\mathrm{H}-\mathrm{Q}(\mathrm{V})(62 \mathrm{msec}$.$) intervals. The right atrial$ pacing at a rate of $120 / \mathrm{min}$. induced a progressive lengthening of the $\mathrm{P}(\mathrm{A})-\mathrm{H}$ interval and the nonconducted beat was dropped between the $\mathrm{P}$ and $\mathrm{H}$ waves (Wenckebach period between the $\mathrm{P}$ and $\mathrm{H}$ waves). With intraverious injection of isoproterenol there was a shortening of the $\mathrm{P}(\mathrm{A})-\mathrm{H}$ interval, but the $\mathrm{H}-\mathrm{Q}(\mathrm{V})$ interval was remained unchanged. Administration of atropine sulfate before meal and propranolol after meal resulted in a transient improvement, but cannot prevent the attack completely. A permanent demand pacemaker was implanted after obtaining excellent results with a temporary transvenous demand pacemaker for the periods of 2 weeks (Fig. 11). The patient has returned to the previous job without any discomfort or attack for the past 2 years.

Case 4. S. N.

A 60-year-old woman, who was also reported in brief previously, 6 has had repetitive episodes of ventricular tachycardia (Fig. 12) not prevented with the conventional antiarrhythmic drugs for the past 4 months. There was no evidence suggesting recent myocardial infarction. During the normal sinus rhythm with occasional premature ventricular contracions extermal transvenous pacemaking was started with a catheter electrode in the right ventricle at a fixed rate $(70$ per minute) slightly faster than her sinus rhythm. The heart was immediately captured by the electrical stimuli, which were continued in spite of runs of ventricular tachycardia for the following 4 days. The ventricular irritability
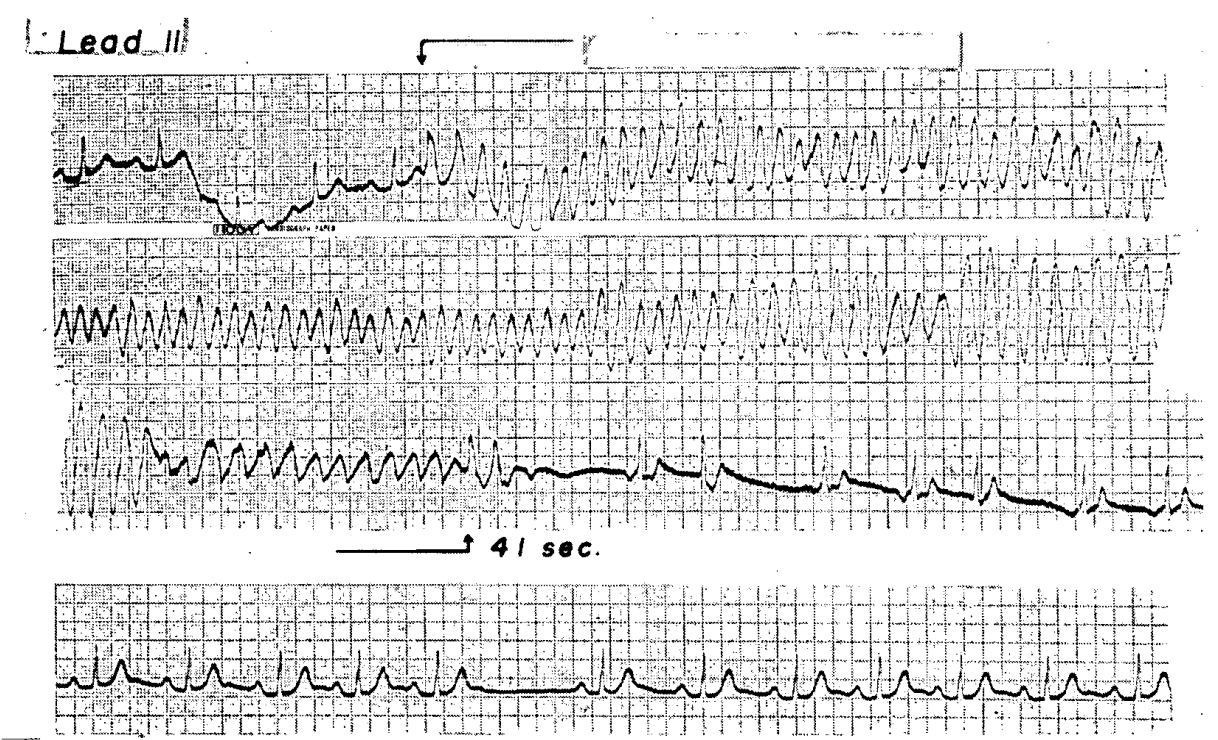

Fig. 7. Electrocardiogram during an episode of ventricular tachyarrhythmia. Case 3, Y. S. Lead II.

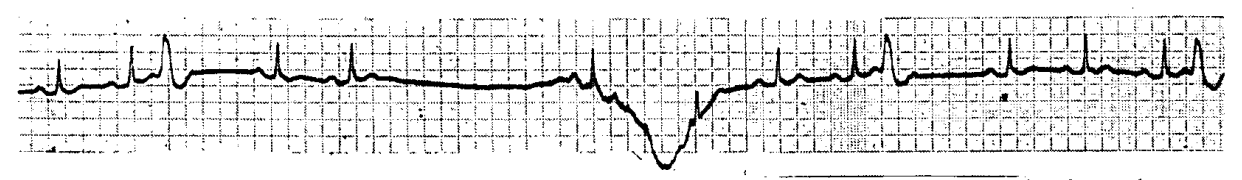

Fig. 8. Thirty minutes after breakfast. Case 3, Y. S. Sinoatrial block and premature ventricular contractions. 
1
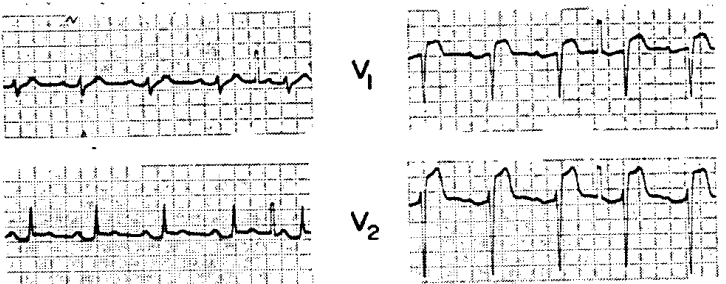

$\mathrm{V}_{2}$

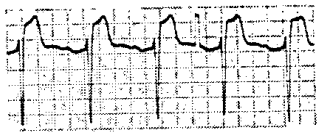

III
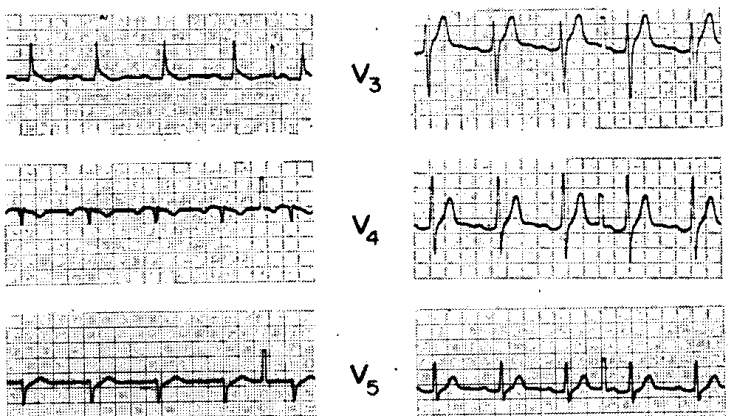

$v_{5}$
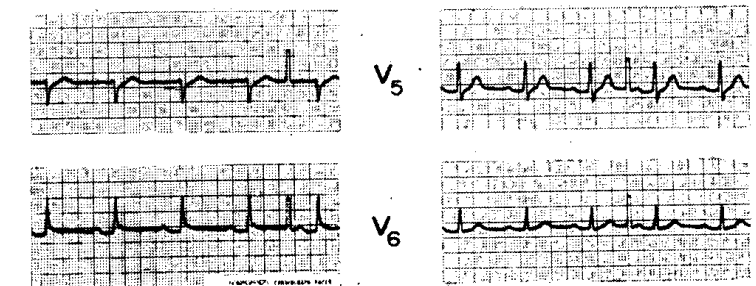

\section{$\checkmark$}

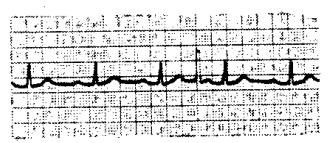

Fig.9. Twelve leads electrocardiogram. Case 3, Y. S. First degree A-V block and queer elevation of $\mathrm{S}-\mathrm{T}$ segment in leads II, aVF and $\mathrm{V}_{1-2}$.
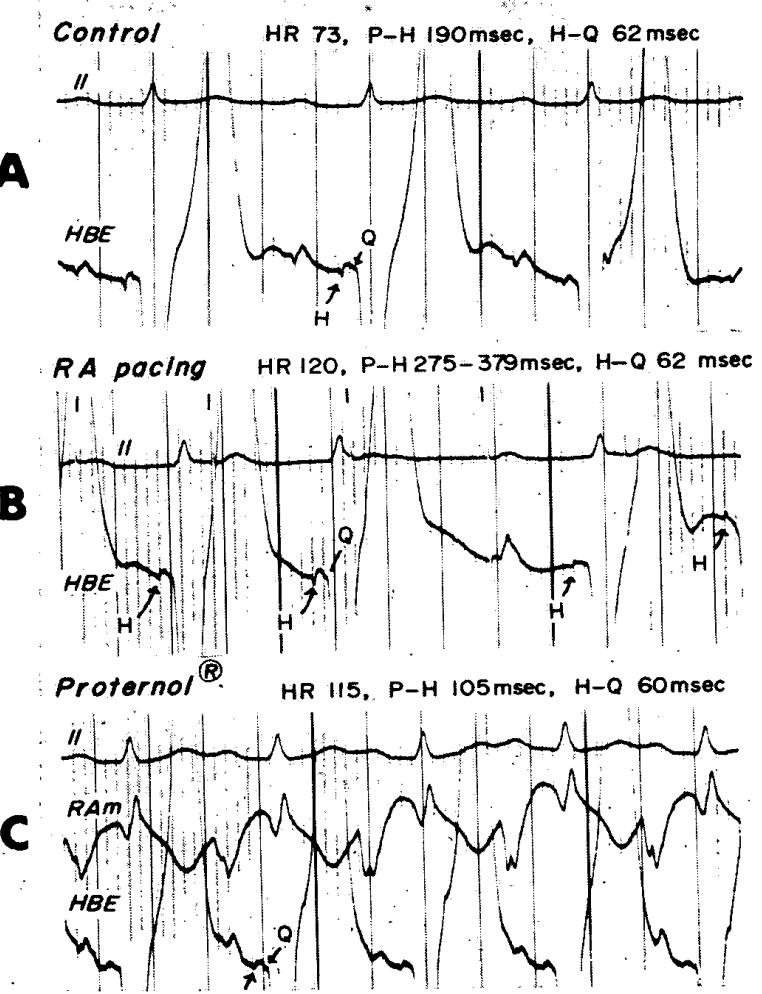

Fig.10. His bundle electrogram (HBE). Case 3, Y. S. A. Control recording. Lengthening of P-A and $\mathrm{H}-\mathrm{Q}$ intervals. B. Right atrial pacing at a rate of 120 per minute. Wenckebach type of block between $P$ and $H$ waves. No change in $H-Q$ interval. C. Sinus tachycardia by intravenous isoproterenol (Proternol ${ }^{\circledR}$ ). Shortening of $\mathrm{P}-\mathrm{H}$ interval and no essential change in $\mathrm{H}-\mathrm{Q}$ interval. II: Lead II electrocardiogram. I: Electrical stimuli. gradually subsided until a stable ventricular capture by the electrical stimuli was finally achieved 36 hours after the onset of pacing (Fig. 13). The catheter electrode was removed after 4 days of pacemaking. The electrocardiogram now revealed the first degree A-V block (P-Q: $0.28 \mathrm{sec}$.), marked left axis deviation (ÂQRS $=-60^{\circ}$ ), and right bundle branch block (Fig. 14). The normal sinus rhythm persisted for several months. The patient refused implantation of a permanent pacemaker and eventually died suddenly at home.

Cas 5. M. O.

A 61-year-old woman with a history of hypertension developed a ventricular parasystolic tachycardia with a rate of 100 per minute. Sinus beats at a rate of 59 per minute occasionally reached the ventricles during a $2: 1$ exit block in the ventricular ectopic rhythm. The interval interrupted by a sinus beat measured a simple multiple of an ectopic period (Fig. 15). The His bundle electrogram (Fig. 16 upper) revealed lengthening of the $\mathrm{P}(\mathrm{A})-\mathrm{H}$ interval (170 to $180 \mathrm{msec}$.) and a normal $\mathrm{H}-\mathrm{Q}(\mathrm{V})$ interval (43 msec.) in a sinus beat. The QRS complex of the ventricular ectopic rhythm was not preceded by the $\mathrm{P}$ waves or $\mathrm{H}$ waves. In the unipolar intra-atrial electrogram (UAE) (Fig 16 lower) the $P$ waves and the wide QRS complexes were recorded regularly and independently at a rate of 75 and 105 per minute, respectively, that being another evidence of ventricular parasystolic tachycardia. The right atrial pacing at a rate equal to or exceeding that of the ventricular ectopic rhythm (107 per minute) succeeded to capture the ventricle but failed immediately when the pacing rate was slowed slightly (102 per minute) (Fig. 17). In this case lidocaine was always effective to eliminate the ventricular ectopic beats and to regain the normal sinus rhythm.

\section{Discussion}

When ventricular irritability arises in the presence of A-V block, the use of conventional antiarrhythmic drugs, cardiac depressants, is contraindicated because these agents may suppress the escape foci and precipitate either life-threatening cardiac standstill or ventricular arrhythmias. It is well known that ventricular irritability in complete A.V block can be suppressed by accelerating the basic idioventricular rhythm. More rapid heart rates are said to reduce ventricular irritability by (1) shortening 


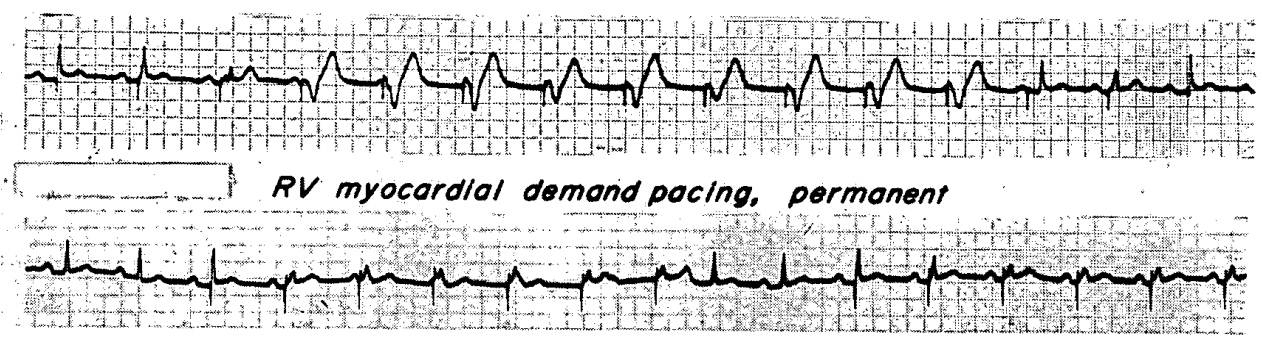

Fig.11. Case 3, Y. S. Electrocardiograms during right ventricular endocardial pacing with temporary demand pacemaker (upper), and myocardial pacing with permanent demand pacemaker (lower). No ventricular irritability seen.

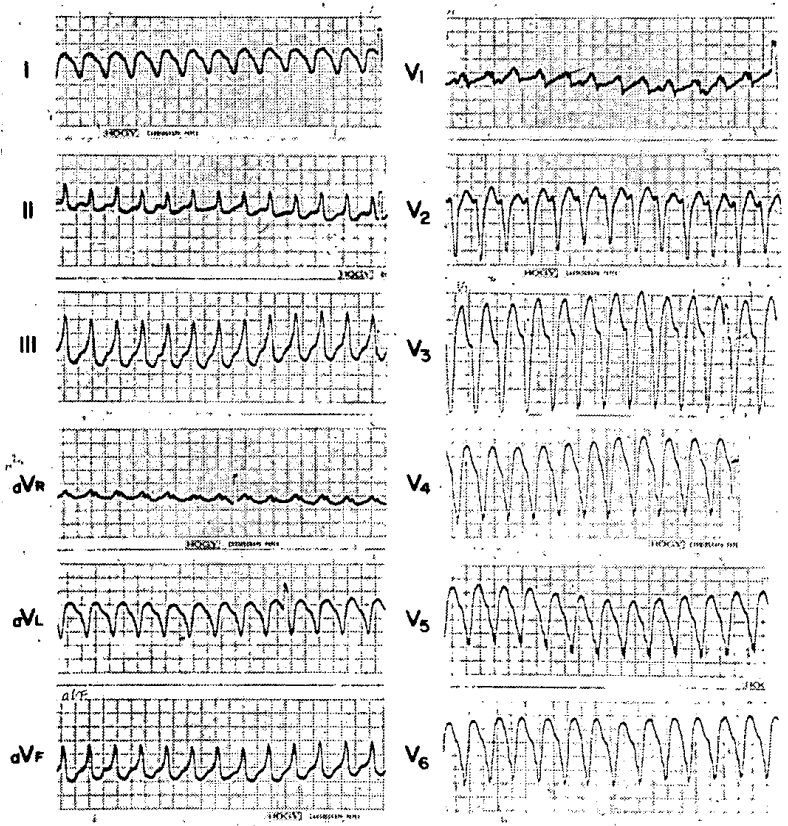

the responsive phase of the cardiac cycle to permit less time for multiple foci to disrupt the ventricular rhythm, (2) increasing coronary blood flow ${ }^{17}$ and (3) preventing asynchrony of recovery of excitability in the myocardial cells! ${ }^{8,19}$ Intravenous isoproterenol and epinephrine may be used for this purpose, ${ }^{7}$. but occasionally they may themselves induce ventricular irritability. There is no doubt that a safer way of treatment is to pace the ventricles electrically as in Case 1.

Pacing the heart at rates of 60 to 80 per minute usually prevents the recurrence of the tachyarrhythmias in patients with the basic idioventricular rate less than 50 per minute due to complete A-V block, because these rates suffice to prevent escape tachyarrhythmias. The same can be applied to the patient with extreme sinus bradycardia in the absence of complete A-V

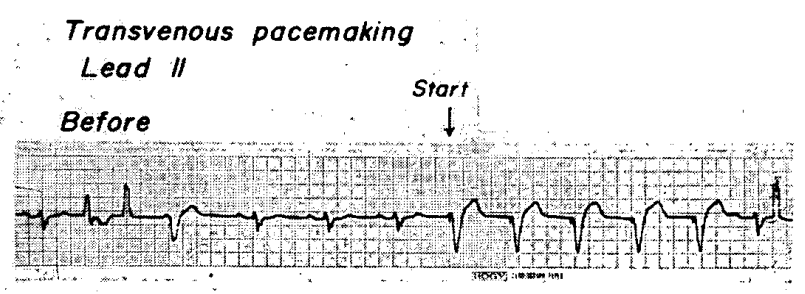

\section{2hr. after}

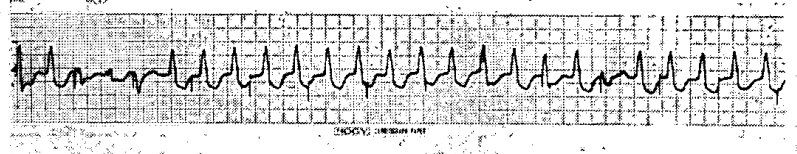

$24 \mathrm{hr}$. after

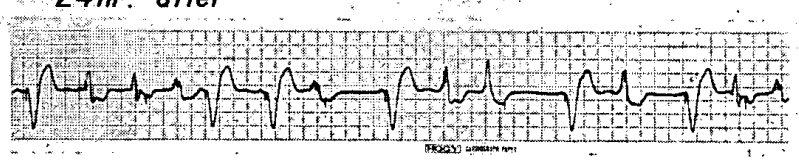

$36 \mathrm{hr}$. after

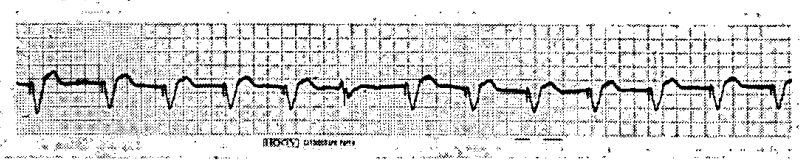

Fig. 13. Serial electrocardiograms during transvenous pacemaking. Case $4, \mathrm{~S} . \mathrm{N}$. Continued pacemaking during runs of ventricular tachycardia eliminated gradually ventricular irritability. Stable ventricular capture by electrical pacemaking was eventually obtained 36 hours after the onset of pacing.

block such as Case 2 .

It is interesting to notice in Case 2 that increase in the heart rate exceeding 75 per minute by intravenous isoproterenol always induced the A.V junctional rhy thm which usually initiated ventricular irritability (Fig. 3, 4), while a direct stimulation of the right atrium by electric pacemaker at rates up to 100 per minute caused neither $\mathrm{P}(\mathrm{A})-\mathrm{H}$ prolongation nor $\mathrm{A}-\mathrm{V}$ block. This may suggest that the sinus node or sinoatrial junction is so sick that cannot be tolerated to fire the stimuli at a rate faster than 75 per minute. During excercise the sinus rate never exceeded 60 per minute. The atrioventri- 


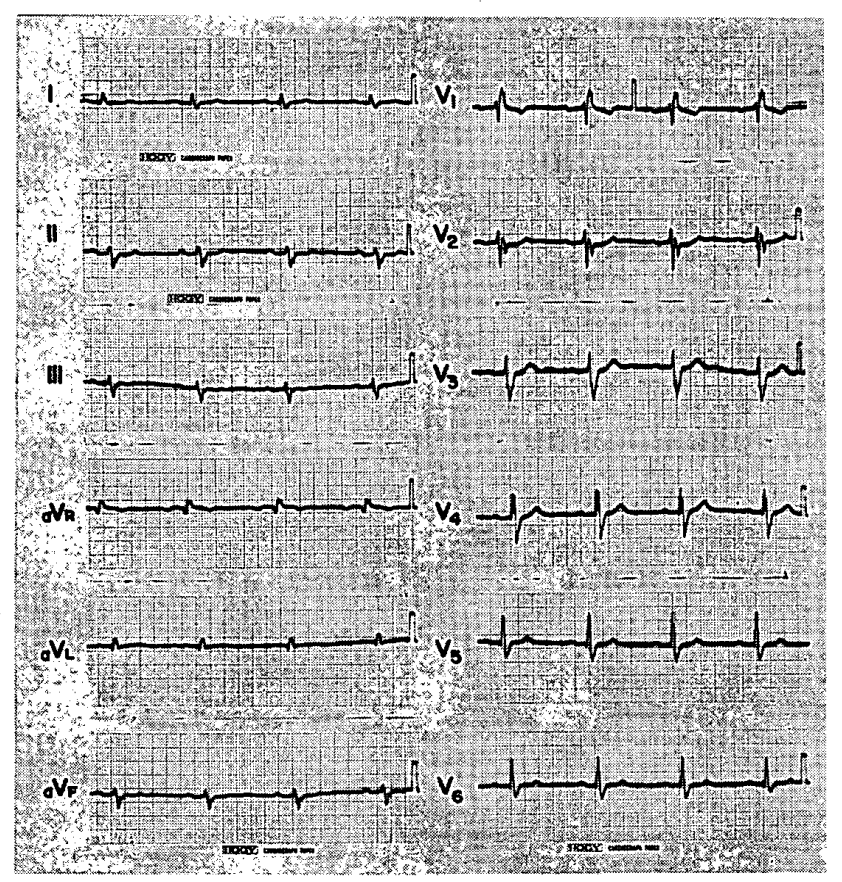

Fig.14. Twelve leads electrocardiogram forty two days after the cessation of electrical pacing. Case 4, S. N. First degree A-V block, marked left axis deviation and right bundle branch block.

cular node and the His-Purkinje system seem to be less involved on the basis of normal $\mathrm{P}(\mathrm{A})-\mathrm{H}$ and $\mathrm{H}-\mathrm{Q}(\mathrm{V})$ intervals. It is concluded that this is a case of sick sinus syndrome and that the treatment of choice is to pace the heart electrically on the exactly same reasons described previously in Case 1. In Case 2 the ventricle was selected for a permanent pacing site, because there is no guarantee that the atrioventricular node is remained to be intact in the near future.

In Case 3, in contrast with Case 2, the atrioventricular node and the His-Purkinje system are thought to be mainly involved because of a lengthening of the $\mathrm{P}(\mathrm{A})-\mathrm{H}$ and $\mathrm{H}-\mathrm{Q}(\mathrm{V})$ intervals, and the finding in the right atrial pacing. In this situation it is highly likely that, when the escape beat is needed with some reasons, the escape to the supraventricular pacemaker is unable and the ventricular irritability initiated. Although the ventricular irritability is not necessarily initiated by the sinus bradycardia or sinoatrial block (Fig. 7), with the hope that maintaining the heart rate at a physiological level will eliminate the need for the escape rhythm which originates the ventricular tachyarrhythmia, a permanent pacemaker was implanted with an excellent result.

In retrospect Case 4 is diagnosed as probably having bilateral bundle branch block or trifascicular block on the basis of the electrocardiogram showin the first degree A.V block, marked left axis deviation, and right bundle branch block $^{20,21}$ (Fig. 14). Therefore, the $\mathrm{P}(\mathrm{A}) \cdot \mathrm{H}$ and the $\mathrm{H}-\mathrm{Q}(\mathrm{V})$ intervals might be shown to be prolonged as in Case 3 , if the His bundle electrogram had been examined during her life. She always developed the ventricular tachycardia initiated by increasing ventricular ectopic beats in the absence of obvious bradycardia. Even when the heart rate is normal in a patient with recurrent ventricular tachycardia, overdriving can prevent the initiation of ectopic rhythms by rendering ventricular recovery of excitability sufficiently synchronous to eliminate the development of local potential differences. It is conceivable that this holds especially true in case of some defect in the conduction system, above all the His-Purkinje system, because ventricular repolarization may be easily delayed and asynchronous in such occasions. Overdriving at a physiological rate, 70 per minute, suppressed successfully the ventricular irritability and the consequent bouts of ventricular tachycardia in Case 4.

In Case 5, however, overdriving was eventually unsuccessful to suppress the ventricular parasystolic tachycardia at a rate of physiological range. Effective suppression by lidocaine in this case as well as in Case 2 (Fig. 3) may be related to the intact conduction in the His-Purkinje system assumed by a normal $\mathrm{H}-\mathrm{Q}(\mathrm{V})$ interval. In order to maintain a regular sinus rhythm after the elimination of ectopic foci by antiarrhythmic

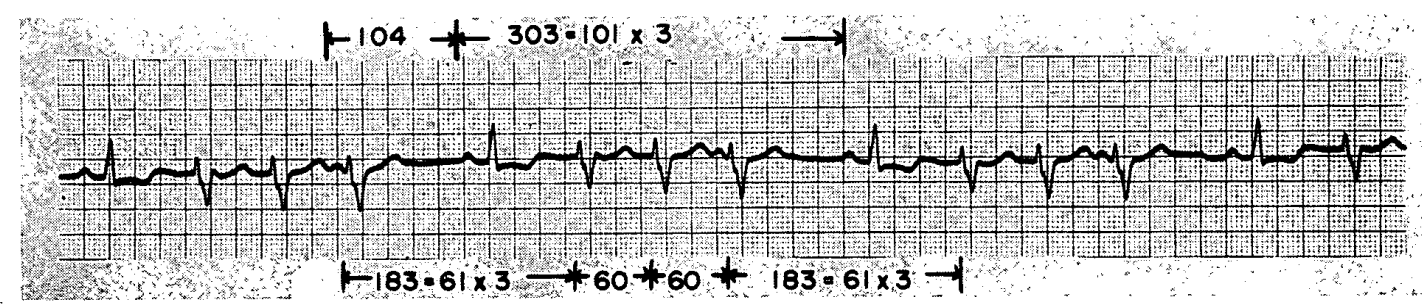

Fig.15. Ventricular parasystolic tachycardia with a rate of 100 per minute. Case 5 , M. O. Sinus beats reached the ventricle whenever exit block in ventricular parasystolic rhythm exists. The rate of sinus rhythm is 59 per minute. Lead II. Numbers represent hundredths of a second. 


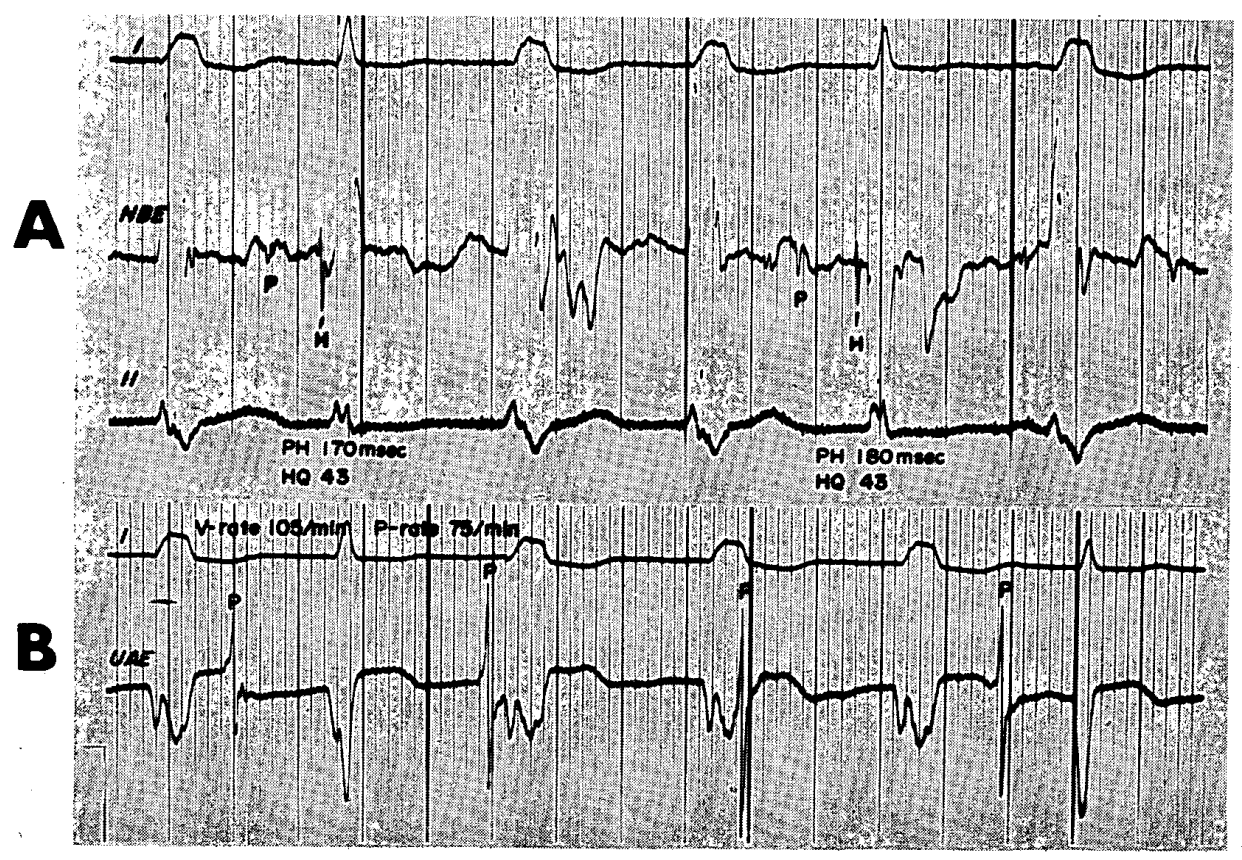

Fig. 16. Case 5, M. O. A. His bundle electrogram (HBE) and standard electrocardiogram (leads I and II). Prolonged $\mathrm{P}-\mathrm{H}$ and normal $\mathrm{H}-\mathrm{Q}$ intervals in sinus beats. No $\mathrm{H}$ waves precede $\mathrm{QRS}$ complexes in ventricular parasystolic tachycardia. B. Unipolar intraright atrial electrogram (UAE) and standard electrocardiogram (Lead I). P waves and QRS complexes appear regularly and independently, the latter being much faster than the former.

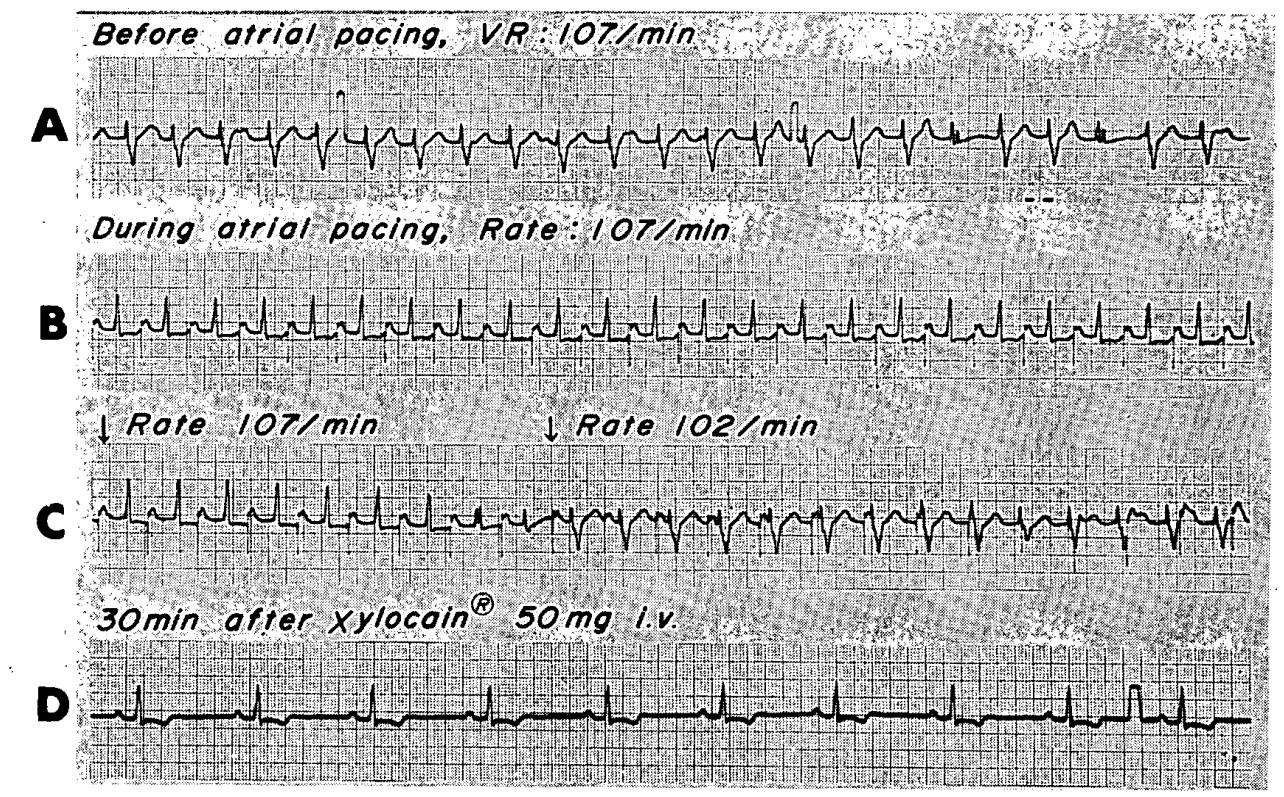

Fig.17. Case 5, M. O. A. Before right atrial pacing ventricular parasy stolic tachycardia with a tate of 107 per minute prevails. There are occasional ventricular fusion beats. B. Right atrial pacing at a rate of 107 per minute captured the heart successfully. C. Ventricular parasystolic tachycardia recurred whenever the atrial pacing rate slows even slightly. D. Intravenous lidocaine (Xylocain ${ }^{\circledR}$ ) suppressed ventricular irritability.

drugs, sinus beats must reach the ventricles without interruption. Otherwise the ventricular irritability would soon recur.

Finally, it should be noted that cardiac pacing at a rate of physiological range may be effective in controling recurrent ventricular tachyarrhythmias in a patient without complete heart block or sinus bradycardia between attacks but with 
defects in the conducting system, especially in the His-Purkinje system. The His bundle electrogram may be of value to determine the indication of cardiac pacing for that particular use by detecting the defective sites in the conducting system, although further studies are needed in this respect.

\section{SUMMARY}

In this series of patients antiarrhythmic drugs failed to and an artificial cardiac pacing was effective to suppress or prevent recurrent ventricular tachyarrhythmias which developed in a patient with (1) bradycardia due to complete heart block, (2) bradycardia due to sick sinus syndrome in the absence of complete heart block, and (3) normal heart rate between attacks of tachyarrhythmia in the presence of the defects in the conducting system, particularly in the HisPurkinje system. The possible mechanisms responsible for overdrive suppression of an artifical cardiac pacing were discussed. It was proposed as a preliminary report that the His bundle electrogram may be of value in determining the indication of cardiac pacemaking for suppression of recurrent ventricular tachyarrhythmias in a patient with normal heart rate between attacks.

\section{Acknowledgement}

The author would like to express his thanks to Prof. T. Takatsu for his constant encouragement. Permanent pacemakers in Cases 1, 2 and 3 were implanted by Prof. A. Takeuchi and his associates. The author is also grateful to the members of the house staff of the 3rd Medical and the 2nd Surgical Divisions, Osaka Medical College, who participated in the care of the patients reported in this paper.

\section{REFERENCES}

1. ZOLL, P. M., LINENTHAL'A. J., \& ZARSKY, L. R. N.: Ventricular fibrillation: treatment and prevention by external electric currents. New Engl. J. Med. 262: 105, 1960.

2. SOWTON, E., LEATHAM, A., \& CARSON, P.: The suppression of arrhythmias by artificial pacemaking. Lancet 2: 1098, 1964.

3. SCHOONMAKER, F. W., OSTEEN, R. T., \& GREENFIELD, J.C., Jr.: Thioridazine (Mellaril ${ }^{\circledR}$ ). induced ventricular tachycardia controlled with an artificial pacemaker. Ann. Int. Med. 65: 1076, 1966.

4. HEIMAN, D. F. \& HELWIG, J., Jr.: Suppression of ventricular arrhythmias by transvenous intracardiac pacing. JAMA 195: 1150, 1966.

5. LEW, H. T. \& MARCH, H. W.: Control of recurrent ventricular fibrillation by transvenous pacing in the absence of heart block. Amer. Heart J. 73: 794, 1967.

6. KAWAI, C.: Artificial cardiac pacemeker. 1) Medical aspects of implantable cardiac pacemaker.
Jap. Circulat. J. 33: 1577, 1969.

7. FRIEDBERG, C. K., LYON, L. J., \& DONOSO, E.: Suppression of refractory recurrent ventricular tachycardia by transvenous rapid cardiac pacing and antiarrhythmic drugs. Report of seven cases. Amer. Heart J. 79: 44, 1970.

8. BENNETT, M. A. \& PENTECOST, B. L.: Reversion of ventricular tachycardia by pacemaker stimulation. Brit. Heart J. 33: 922, 1971.

9. McCAlliSTER, B. D., McGOON, D. C., \& CONNOLLY, D. C.: Paroxy smal ventricular tachycardia and fibrillation without complete heart block. Report of a case treated with a permanent internal cardiac pacemaker. Amer. J. Cardiol. 18: 898, 1966.

10. KASTOR, J. A., DeSANCTIS, R. W., HARTHORNE, J. W., \& SCHWARTZ, G. H.: Transvenous atrial pacing in the treatment of refractory ventricular irritability. Ann. Int. Med. 66: 939, 1967.

11. COHEN, L. S., BUCCINO, R. A., MORROW, A. G., \& BRAUNWALD, E.: Recurrent ventricular tachycardia and fibrillation treated with a combination of beta-adrenergic blockade and electrical pacing. Ann. Int. Med. 66: 945, 1967.

12. MOSS, A. J., RIVERS, R. J., Jr., GRIFFITH, L. S. C., CARMEL, J. A., \& MILlARD, E. B,, Jr.: Transvenous left atrial pacing for the control of recurrent ventricular fibrillation. New Engl. J. Med. 278: 928, 1968.

13. HORNBAKER, J. H., Jr., HUMPHRIES, J. O., \& ROSS, R. S.: Permanent pacing in the absence of heart block. An approach to the management of intractable arrhy thmias. Circulation 39: 189, 1969.

14. SOWTON, E.: Artificial pacemaking and sinus rhythm. Brit. Heart J. 27: 311, 1965.

15. GREENFIELD, J. C., Jr. \& ORGAIN, E. S.: The control of ventricular tachyarrhythmias by internal cardiac pacing (editorial), Ann. Int. Med. 66: 939, 1967.

16. KAWASAKI, K., YAMASHITA, K., HORI, K., KAWAI, C., TAKATSU, T., IIMORI, Y., \& TAKEUCHI, A.: A case of recurrent ventricular tachycardia and fibrillation treated with a permanent pacemaker. (in Japanese) Shinzo, 4: 1665, 1972.

17. LINENTHAL, A. J. \& ZOLL, P. M.: Prevention of ventricular tachycardia and fibrillation by intravenous isoproterenol and epinephrine. Circulation 27: 5, 1963.

18. HOFFMAN, B. F. \& CRANEFIELD, P. F.: Physiologic basis of cardiac arrhythmias. Amer. J. Med. 37: 670, 1964.

19. HAN, J., MILLET, D., CHIZZONITTI, B., \& MOE, G. K.: Temporal dispersion of recovery of excitability in atrium and ventricle as a function of heart rate. Amer. Heart J. 71: 481, 1966.

20. McNALLY, E. M. \& BENCHIMOL, A.: Medical and physiological considerations in the use of artificial cardiac pacing, Part 1. Amer. Heart J. 75: $380,1968$.

21. ROSENBAUM, M. B., ELIZARI, M. V., LAZZARI, J. O., NAU, G. J., LEVI, R. J., \& HALPERN, M. S.: Intraventricular trifascicular blocks. Review of the literature and classification. Amer. Heart J. 78: $450,1969$. 